The chairman of the committee is able to take matters on board which have not been sorted at a local level. There can be direct communication with the Pan Rotational tutors, and problems can also be taken to the British Post Graduate Medical Federation Meetings, which the chairman attends.

There is also a social side to the activities, with regular rotational meals, generally sponsored by a drug company, and a recent jazz evening, which was open to all trainees and all consultant supervisors on the rotation.

One of the main difficulties encountered in this region is communicating effectively with each trainee. With the mailing list for the junior doctors' committee meetings being approximately 120 individuals, and the lack of designated secretarial support to the committee, this places a great strain on the individuals responsible for mailing. The idea of a newsletter and a logo which is in use in Liverpool seems very useful. However the experience provided to the committee members in administration and working with the every day politics of a training scheme are invaluable. Also the one day introductory course for new SHOs, which the chairman organises twice a year, the review of the end of placement assessment forms and the review of the logbook system used in South West Thames, have been important recent activities.

We would urge the setting up of junior doctor representation at all levels in other parts of the country, as the experience in South West Thames has been extremely profitable both to trainees and to their educational supervisors in improving the overall quality of trainee experience.

Chairman, Junior Doctors' Committee

TOM MCCLINTOCK

St George's Hospital Rotations

\section{A trainee's view of hospital management}

DeAr Sirs

The CTC (1990) has stressed the importance of management training for psychiatrists. As a registrar, it seems appropriate to record my impressions of hospital management before they are coloured by formal learning of management theory.

Junior doctors are privileged to occupy a unique niche in the hospital. We are closely involved with a variety of staff on a daily basis, but are not part of their management lines. This permits candid discussion, allowing us to accurately gauge staff feeling. "Manager-bashing" is a popular theme, and although this is hardly a new phenomenon, it is set against a background of low morale, resentment towards the ever-expanding management body, continual complaints of inadequate ward staffing levels, and high rates of staff sickness. Managers tend to be perceived as opponents who do not appreciate their staff, and who are interested only in administration, and not in patient care. Staff often do not feel they can trust their line managers enough to express their opinions honestly. This may or may not be the reality of the situation, but the sentiments themselves are very real.

So where is the system failing, to create such resentment? It appears that hospitals often focus on administrative issues to the exclusion of what must surely be the core of effective management; man management. Many managers seem to take for granted the staff under them. Either the principles of man management are not being adequately taught, or they are being ignored by hard-pressed managers. This must have implications for the training of psychiatrists in this area.

In making these, perhaps naive, generalisations, I myself have fallen into the obvious trap of managerbashing, but I would stress that this is not aimed at specific individuals or hospitals. I am simply recounting what $I$ and my peers regrettably see in many hospitals, and hope my comments may initiate constructive discussion, if only to prove me wrong. The currency of our business is patient care, and our greatest asset is our staff. If we look after them, surely we stand to gain better value for money in our ever-dwindling budgets?

Staffordshire

M. R. AtKins

\section{Reference}

Royal College of Pyschiatrists (1990) The CTC Working Party Report on Management Training. Psychiatric Bulletin, 14, 373-377.

\section{Familial thyroid disorder presenting as folie à deux \\ DEAR SIRS}

I would like to draw your attention to a case of familial thyroid disorder which presented as a folie à deux or induced psychosis. There have been numerous case reports of folie $\dot{a}$ deux in the literature. The occurrence of psychosis in overactive and underactive thyroid disorders is also well documented.

\section{Case history}

Mr X, aged 20, has mild learning difficulties, and lives with his mother and stepfather. The mother and maternal grandfather have hypothyroidism. The mother is clinically myxoedematose. The patient was expelled from special school, aged 14, having threatened a teacher with a knife. He was prevented from leaving the family home by his mother for the ensuing three years. He was first seen by a psychiatrist from the community team for learning difficulties when aged 17 . 